\title{
Durability of Mo-Ni intermetallic compounds in the hydro- gen evolution reaction
}

\author{
L. Rößner ${ }^{[a]}$, H. Schwarz ${ }^{[b]}$, I. Veremchuk ${ }^{[c]}$, R. Zerdoumi ${ }^{[a]}$, Th. Seyller ${ }^{[b]}$ and M. Armbrüster ${ }^{*[a]}$
}

[a] Professur Materialien für innovative Energiekonzepte Chemnitz University of Technology

Straße der Nationen 62, 09111 Chemnitz, Germany

E-mail: marc.armbruester@chemie.tu-chemnitz.de

[b] Professur Experimentalphysik mit Schwerpunkt Technische Physik

Chemnitz University of Technology

Straße der Nationen 62, 09111 Chemnitz, Germany

[c] Chemische Metallkunde

Max-Planck Institute für Chemische Physik fester Stoffe

Nöthnitzer Str. 40, 01187 Dresden, Germany

Supporting information for this article is given via a link at the end of the document.

\begin{abstract}
Molybdenum-nickel materials are catalysts of industrial interest for the hydrogen evolution reaction (HER). This contribution investigates the potential influence of ordered crystal structures on the catalytic activity. Well-characterized surfaces of the single-phase intermetallic compounds $\mathrm{Ni}_{7} \mathrm{Mo}_{7}, \mathrm{Ni}_{3} \mathrm{Mo}$ and $\mathrm{Ni}_{4} \mathrm{Mo}$ were subjected to accelerated durability tests (ADTs) and thorough characterization to unravel, whether crystallographic ordering affects the activity. Due to their intrinsic instability, molybdenum is leached resulting in higher specific surface areas and nickel-rich surfaces. The gain in surface area scales with the applied potential and the molybdenum content of the pristine samples. The nickel-enriched surfaces are more prone to form $\mathrm{Ni}(\mathrm{OH})_{2}$ layers, which leads to deactivation of the Mo-Ni materials. The crystal structure of the intermetallic compounds has, due to the intrinsic instability of the materials in alkaline media, no effect on the activity. The earlier as durable identified $\mathrm{Ni}_{7} \mathrm{Mo}_{7}$ proves to be highly unstable in the applied ADTs. The results indicate that the enhanced activity of unsupported bulk Mo-Ni electrodes can solely be ascribed to increased specific surface areas.
\end{abstract}

\section{Introduction}

Supplying our society with the continuously increasing demand of energy while simultaneously replacing the limited resources of fossil fuels by suitable renewable energy carriers is one of the major challenges of our century. ${ }^{[1,2]}$ Therefore, massive energy storage of generated electricity from renewable and sustainable resources on a scale of gigawatt-hours in North America, Europe and Asia will be needed. ${ }^{[3]}$ In this context, hydrogen generation by water electrolysis is a feasible way to convert electrical into chemical energy. ${ }^{[4]}$ The resulting hydrogen can be stored or further converted by power-to-X concepts which allows to liberate the hydrogen on-demand to drive fuel cells. ${ }^{[5]}$

The challenge for economical hydrogen production by water electrolysis is related to the high overvoltage, resulting in uncompetitive energy costs. Therefore, currently only about $4 \%$ of the global hydrogen production are realized by water splitting. ${ }^{[6]}$ To overcome the energy obstacle, development and utilization of highly active, low-cost and stable catalytic materials with low overpotential is needed. State-of-art catalysts in acidic media are still based on platinum and its alloys. ${ }^{[7-9]}$ Because the exhaustive industrial application of platinum is restricted by prize and availability, ${ }^{[10]}$ development of competitive platinum-free catalysts for the electrochemical hydrogen evolution is here required.

In alkaline media on the other hand, nickel-based materials show comparable or even superior activity over platinum, ${ }^{[8,11]}$ and according to recent comparisons, the alkaline electrolysis technology is able to compete with modern electrolysis on polymer electrolyte membranes (PEMs). ${ }^{[12,13]}$ Various combinations of nickel with different elements ( $\mathrm{Al}, \mathrm{Fe}, \mathrm{Mo}, \mathrm{Ti}, \mathrm{V}$ or $\mathrm{Zr}$ ) were tested to achieve better performance, prevent hydride formation and reach higher durability. ${ }^{[14]}$ The addition of molybdenum is a common way to achieve lower overvoltage as well as better durability and was investigated ${ }^{[15-17]}$ and patented ${ }^{[18-20]}$ by BP in the early 1980's. Most studies since then are dealing with electrodeposited coatings of Mo-Ni. ${ }^{[21-23]}$ Numerous studies employing nanoparticulate synthesis strategies were published in recent years, reporting highly active and durable intermetallic Mo-Ni compounds. ${ }^{[11,24]}$ Results from these high surface-area catalysts are often hard to compare, especially as the materials involve different supports. Resulting from the vast literature reporting on Mo-Ni hydrogen evolution reaction (HER) catalysts, numerous explanations for their high activity have been brought forward.

While some studies agree upon high specific surface areas being at least one factor for higher activity, ${ }^{[11,25]}$ other influences like electronic effects ${ }^{[26-28]}$ or the contributions of bifunctional mechanisms ${ }^{[28-30]}$ are also under discussion. In addition, the higher activity got attributed to the sole presence of intermetallic compounds. ${ }^{[11,27,30,31]}$ So far, systematic studies on flat surfaces of unsupported bulk-materials to unravel the intrinsic properties are scarce. Chialvo et al. investigated disordered Mo-Ni substitutional alloys ( $\mathrm{Cu}$ type of crystal structure) with molybdenum contents up to 25 at. $\%$. ${ }^{[26]}$ A correlation of the activity with the lattice parameter was excluded and the authors suggested an electronic effect to be responsible for higher activities for materials with more than 10 at. $\%$ molybdenum. Jaksic et al. investigated the HER kinetics of mixed-phase Mo-Ni samples and suggested a volcano-type relationship of activity vs composition, having its maximum at $\mathrm{Ni}_{7} \mathrm{Mo}_{7}{ }^{[27]}$ which was ascribed to an interionic synergism. ${ }^{[32]}$ Those studies neglected contributions from electrode instabilities, resulting in altered surface compositions 
and roughening. Schalenbach et al. revealed the latter two to be of utmost importance for the durability of substitutional Mo-Ni alloys and concluded that activity gains in the Mo-Ni system are a result of selective molybdenum leaching, leading to nickel surfaces with high specific surface area. ${ }^{[25]}$ This does not necessarily have to hold true for structurally ordered intermetallic compounds, as Csernica et al. found a higher surface-specific activity for $\mathrm{Ni}_{7} \mathrm{Mo}_{7}$ compared to a Mo-Ni alloy. ${ }^{[31]}$ Still, the latter study was conducted on porous samples, and the surface area was evaluated by ex situ physisorption measurements.

Here, the role of intermetallic Mo-Ni compounds, i.e. their ordered crystal structure, is investigated concerning the activity and durability of Mo-Ni electrode materials. To enable a clear distinction from other factors (e.g. interactions with the support, exposed surface area or nanoparticle morphology), polished polycrystalline bulk intermetallic compounds are used. The specimens have the additional benefit that a well-defined starting point for all analysis methods can be obtained reproducibly by polishing, thus establishing a reference state for the different investigations (Scheme 1).

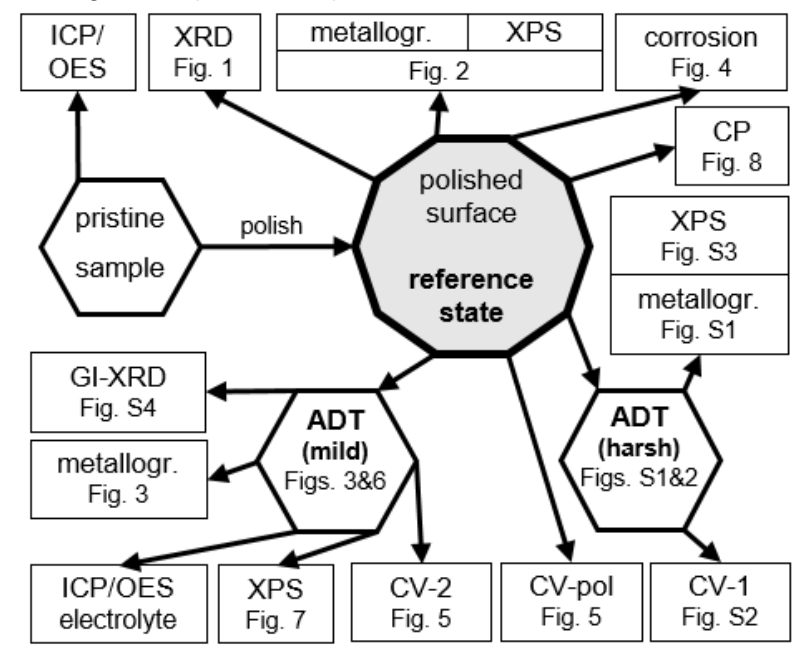

Scheme 1. Organisation of this contribution emphasising the reference state.

Following this scheme, full characterization of the as-prepared bulk intermetallic Mo-Ni compounds - as well as the substitutional alloy Ni80Mo20, elemental nickel, and molybdenum for comparison - is conducted, followed by two different accelerated durability tests (ADTs), corrosion studies and characterization of the electrode materials as well as the electrolytes.

\section{Results and Discussion}

\section{Sample Characterization}

The substitutional alloy Ni80Mo20 (Cu type of crystal structure ${ }^{[33]}$ ) as well as the intermetallic compounds $\mathrm{Ni}_{4} \mathrm{Mo}$ ( $\mathrm{Ni}_{4} \mathrm{Mo}$ type of crystal structure ${ }^{[34]}$ ) and $\mathrm{Ni}_{3} \mathrm{Mo}\left(\mathrm{Cu}_{3} \mathrm{Ti}\right.$ type of crystal structure ${ }^{[35]}$ ) were synthesized by arc melting and consecutive temperature treatment within the respective temperature stability windows of the individual phases in evacuated quartz-glass ampoules. $\mathrm{Ni}_{7} \mathrm{Mo}_{7} \quad\left(\mathrm{Mo}_{3}\left(\mathrm{Mo}_{0.8} \mathrm{Ni}_{0.2}\right)_{5} \mathrm{Ni}_{6}\right.$ type of crystal structure ${ }^{[36]}$ had to be prepared by chemical vapor transport reaction, followed by spark-plasma-sintering (SPS) to obtain dense samples. Nevertheless, in comparison to the samples prepared by arc melting, the obtained $\mathrm{Ni}_{7} \mathrm{Mo}_{7}$ pellets had a porous structure.
The single-phase status of all samples was confirmed by powder $X$-ray diffraction in reflection geometry on metallographically prepared samples (Fig. 1a), i.e. the reference state from which all further electrochemical testing was conducted (Fig. S1).

Using polarized light, different crystallite orientations are observed, due to the optical anisotropy of the non-cubic crystal structures (Fig. 1b-d). The compositions of the pristine samples as determined by inductively coupled plasma optical emission spectroscopy (ICP/OES) result in $\mathrm{Ni}_{80.2} \mathrm{Mo}_{19.8}, \quad \mathrm{Ni}_{81.1} \mathrm{Mo}_{18.9}$, $\mathrm{Ni}_{75.6} \mathrm{Mo}_{24.4}$ and $\mathrm{Ni}_{49.0} \mathrm{Mo}_{51.0}$ for Ni80Mo20, $\mathrm{Ni}_{4} \mathrm{Mo}, \mathrm{Ni}_{3} \mathrm{Mo}$ and $\mathrm{Ni}_{7} \mathrm{Mo}_{7}$, respectively. This agrees with the nominal compositions used for synthesis.

As heterogeneous catalysis takes place at the surface, the nearsurface region was characterized by X-ray photoelectron spectroscopy (XPS). The samples were not cleaned by sputtering before XPS investigation for two reasons. First, the results would not be representative for the as-polished state of the materials to be used in electrochemical experiments. Second, it is known that sputtering of crystalline materials leads to structural changes of the surface layers making it necessary to anneal the samples prior to surface investigations, to retain the initial structures. ${ }^{[37]}$ The latter is especially difficult for ordered intermetallic compounds, as for every compound an individual temperature program after sputtering has to be developed.

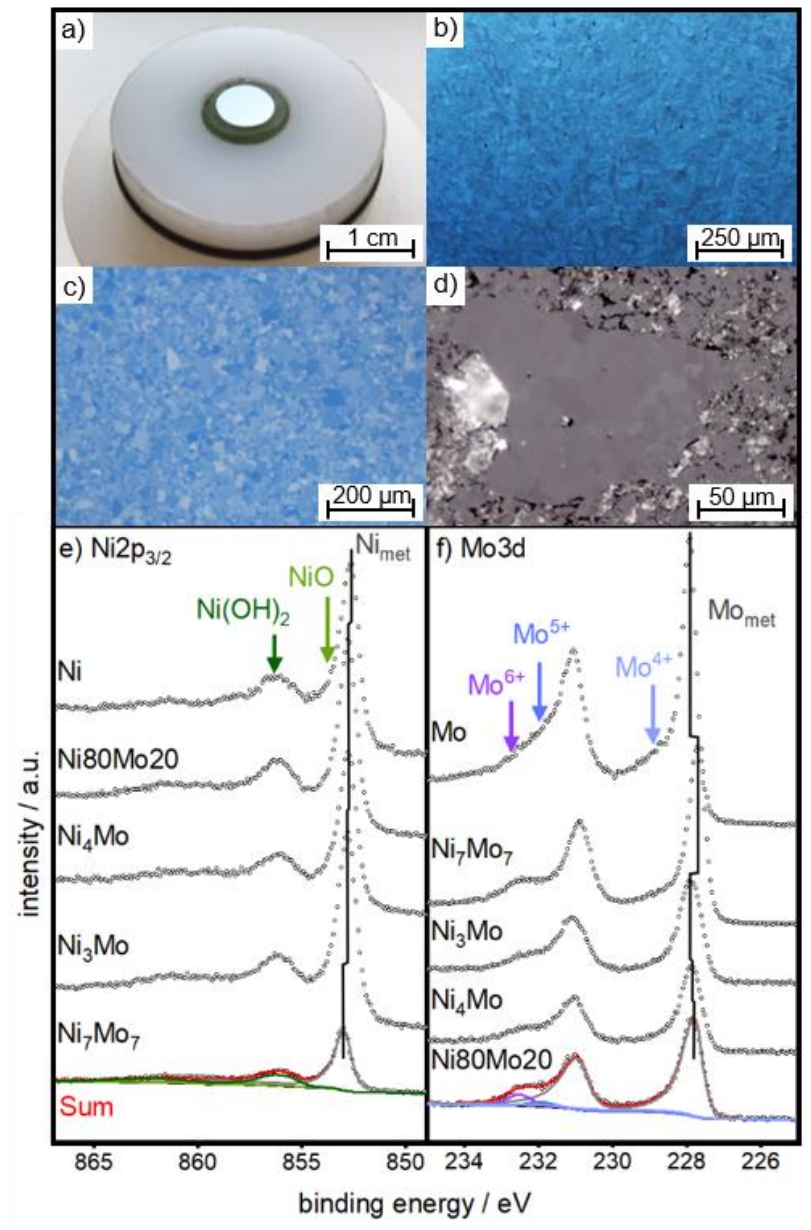

Figure 1 Photograph of the embedded nickel electrode (a) and optical micrographs taken (polarized light) of $\mathrm{Ni}_{4} \mathrm{Mo}$ (b), $\mathrm{Ni}_{3} \mathrm{Mo}$ (c) and $\mathrm{Ni}_{7} \mathrm{Mo}_{7}$ (d). XP spectra of the samples in the Ni2p $\mathrm{p}_{3 / 2}(\mathrm{e})$ and Mo3d (f) range. The deconvolution of measured spectra into individual contributions is shown exemplarily at the bottom. For 
each species, the position of the most intense signal is given by arrows.

The Ni2 $p_{3 / 2}$ spectrum (Fig. 1e) of the elemental nickel electrode can be described by a combination of metallic $\mathrm{Ni}(852.6 \mathrm{eV})$, $\mathrm{NiO}(855.7 \mathrm{eV})$ and $\mathrm{Ni}(\mathrm{OH})_{2}(856.3 \mathrm{eV})$, demonstrating that polished surfaces are already partially oxidized. The assignment and discrimination of $\mathrm{NiO}$ from $\mathrm{Ni}(\mathrm{OH})_{2}$, even though the charge of nickel being virtually the same in those species, is done based on multi-peak line-shapes described by Biesinger et al. ${ }^{[38]}$ and the corresponding fitting constraints are given in the Supporting Information (Table S1).

While the binding energies of oxidized species remain unchanged for all Mo-Ni electrodes, the (inter-)metallic signals of nickel are shifted to higher binding energy with respect to elemental nickel. The shift scales monotonically with the molybdenum content. Neglecting the change of crystal structures, which has an influence on the electronic band structure, this shift can be explained by a partial electron transfer from nickel towards molybdenum. This agrees with the Pauling electronegativity values of the individual elements $\left(X_{N i}=1.91\right.$ and $X_{M O}=$ $2.16^{[39]}$ ). The resulting binding energies of the (inter-)metallic nickel Ni2p $\mathrm{p}_{3 / 2}$ signals are 852.7, 852.7, 852.8 and $853.0 \mathrm{eV}$ for $\mathrm{Ni}_{80} \mathrm{Mo}_{20}, \mathrm{Ni}_{4} \mathrm{Mo}, \mathrm{Ni}_{3} \mathrm{Mo}$ and $\mathrm{Ni}_{7} \mathrm{Mo}_{7}$, respectively.

The Mo3d spectrum (Fig. 1f) of an elemental molybdenum electrode can be deconvoluted into contributions of metallic Mo $(227.9 \mathrm{eV})$ and oxidized species of $\mathrm{Mo}^{4+}(229.3 \mathrm{eV}), \mathrm{Mo}^{5+}$ $(231.9 \mathrm{eV})$ and $\mathrm{Mo}^{6+}(232.5 \mathrm{eV})$. The observed $\mathrm{Mo}^{5+}$ signals are known to emerge due to $\mathrm{X}$-ray irradiation of $\mathrm{Mo}^{6+[40]}$ (the according stoichiometric oxide $\mathrm{Mo}_{2} \mathrm{O}_{5}$ is not stable in air ${ }^{[41]}$ ) and are thus not intrinsic to the samples. A definite assignment of stoichiometric (hydr-)oxides was not done as the available information on molybdenum samples being majorly metallic is too scarce. The expected lower binding energy of (inter-)metallic Mo signals in the Mo-Ni electrodes, even though not monotonically increasing with nickel content, is observed. The Mo3d $d_{5 / 2}$ binding energies of the (inter-)metallic signals are 227.7, 227.8, 227.8 and $227.7 \mathrm{eV}$ for $\mathrm{Ni}_{7} \mathrm{Mo}_{7}, \mathrm{Ni}_{3} \mathrm{Mo}$. $\mathrm{Ni}_{4} \mathrm{Mo}$ and Ni80Mo20, respectively. The binding energies of oxidized Mo-species are identical to the ones on the elemental molybdenum electrode.

\section{Electrochemical Characterization}

The polished electrodes were initially investigated by an ADT protocol cycling the potential between 0.0 and $-0.4 \mathrm{~V}$ vs $\mathrm{RHE}$ (Fig. 2) with the pores of $\mathrm{Ni}_{7} \mathrm{Mo}_{7}$ being closed before each electrochemical experiment with resin to obtain a flat surface (see Experimental Section for details).

After the ADT, the surfaces of the electrodes do not show severe changes. Solely some shadows around the cracks in $\mathrm{Ni}_{4} \mathrm{Mo}$ (Fig. 2c, inset) were observed, stemming from evaporated electrolyte leaving behind $\mathrm{KOH}$. The irregular appearance of $\mathrm{Ni}_{7} \mathrm{Mo}_{7}$ consisting of the intermetallic compound (bright) and resin (dark) did not change to the freshly polished state. The pores still appeared blurry and focusing their bottom was not possible, indicating a retained sealing of those voids with resin. Thus, no optically detectable deterioration takes place during the test.

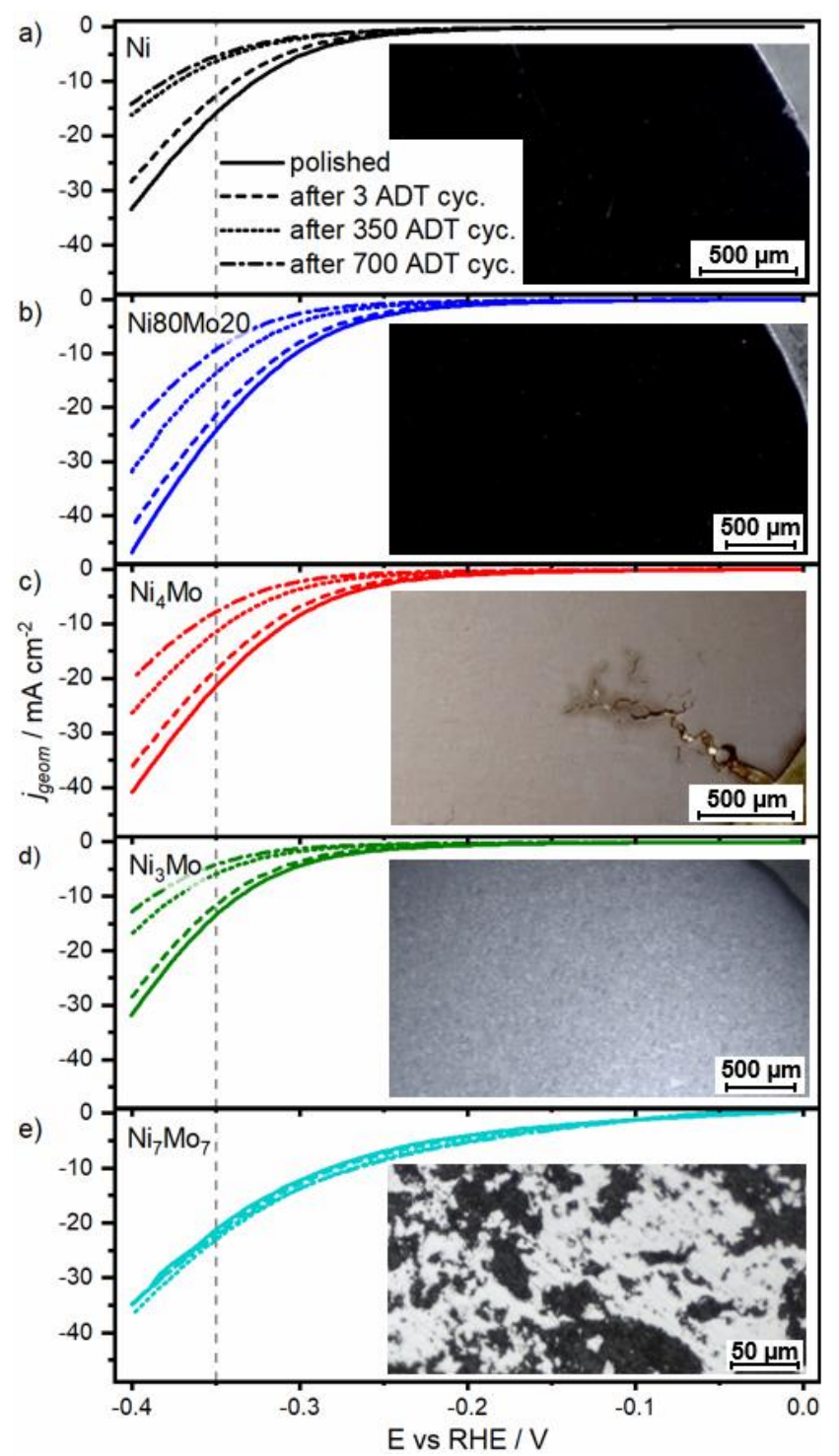

Figure 2 LSV scans of the different electrodes in $1 \mathrm{M} \mathrm{KOH}$ after the respective number of ADT cycles. Micrographs of the electrodes surface after 700 ADT cycles taken under dark field contrast $(a, b)$, polarized light $(c, d)$ and bright field contrast (e) are shown as inset.

The achieved current density on Mo-Ni materials at an overpotential of $350 \mathrm{mV}$ decreased in the sequence of Ni80Mo20 > $\mathrm{Ni}_{4} \mathrm{Mo}>\mathrm{Ni}_{7} \mathrm{Mo}_{7}>\mathrm{Ni}>\mathrm{Ni}_{3} \mathrm{Mo}$. Thus, the disordered Mo-Ni substitutional alloy outperforms elemental nickel and all the investigated ordered intermetallic compounds. This is in contrast to Jaksic et al. who observed a significantly higher activity for $\mathrm{Ni}_{7} \mathrm{Mo}_{7}$ in comparison to the ones containing less molybdenum. ${ }^{[27]}$

Nickel-rich samples showed comparable HER onsets of approximately $-300 \mathrm{mV}$. $\mathrm{Ni}_{7} \mathrm{Mo}_{7}$ on the other hand is already showing gas evolution at lower overpotentials and the cathodic branch can be divided into two different regions. The low-overpotential region shows a shallower slope in comparison to the higher overpotential region, starting from $-300 \mathrm{mV}$. This might be related to a change in reaction mechanism. As this sample has a more defective surface in comparison to the others, exhibiting a higher number of edges, kinks and corners, the geometric current densities in the low overpotential regime are more likely a 
result of morphology enhanced apparent activity, than being intrinsically higher. All nickel-rich electrodes undergo a monotonic deactivation during the ADT, losing more than $50 \%$ of their initial HER activity. In contrast, $\mathrm{Ni}_{7} \mathrm{Mo}_{7}$ shows no significant change of activity over the course of the ADT.

The deactivation behavior is in agreement with the investigations from Schalenbach et al. ${ }^{[25]}$ on multi-phase Mo-Ni materials, while the activity trend is not. The authors of this study chose an upper potential limit of $+0.4 \mathrm{~V}$ vs RHE, thus being more close to industrially relevant conditions, i.e. start-stop cycles of electrolyzers. To see if this influence is significant, the electrodes were subjected to an ADT mimicking this harsher test (Fig. S2).

Similar to the mild protocol ( $E_{\text {upp }}=0.0 \mathrm{~V}$ vs RHE) the materials slightly deactivate within the first three cycles of the harsh ADT protocol. After 347 further cycles the initial activity could be retained for the $\mathrm{Ni}_{4} \mathrm{Mo}$ and Ni80Mo20 samples, while $\mathrm{Ni}_{3} \mathrm{Mo}$ and especially $\mathrm{Ni}$ show an increase in activity. This is in strong contrast to the mild ADT protocol, where the activity decreased monotonically. Subsequent metallographic characterization revealed no changes in the case of nickel, while $\mathrm{Ni}_{4} \mathrm{Mo} \mathrm{showed}_{1}$ an enhanced contrast of individual crystallite orientations in bright field contrast. This indicates a preferential dissolution of certain crystal facets exposed to the electrolyte and indeed $\mathrm{Ni}_{3} \mathrm{Mo}$ and Ni80Mo20 show severe pit corrosion.

$\mathrm{Ni}_{7} \mathrm{Mo}_{7}$ appeared to be much more active in comparison to the nickel-rich samples, with only a slight monotonic decrease in activity. High-magnification micrographs of the surface reveal a non-uniform discoloration of the surface, indicating a severe change of the electrode surface. This is very different to the state after the mild protocol and to the other electrodes.

It can be concluded that the harsh ADT protocol with an upper potential limit of $+0.4 \mathrm{~V}$ leads to an activation of the electrodes, which based on the micrographs is most likely a result of increased surface areas. These findings are in agreement with the results from Schalenbach et al. ${ }^{[25]}$ on Mo-Ni alloys and suggest an insignificant influence of the ordered intermetallic compounds on their catalytic behavior.

To get a better understanding of the electrochemical behavior of Mo-Ni materials, the in situ stability was determined by means of potentiodynamic polarization curves (Tafel slopes) around the open circuit potential (Fig. 3). The corrosion current densities $\left(j_{\text {corr }}\right)$ were determined in different $\mathrm{KOH}$ concentrations from the arithmetic average of the forward and backward scan to minimize the contributions of the charging current. ${ }^{[42]}$

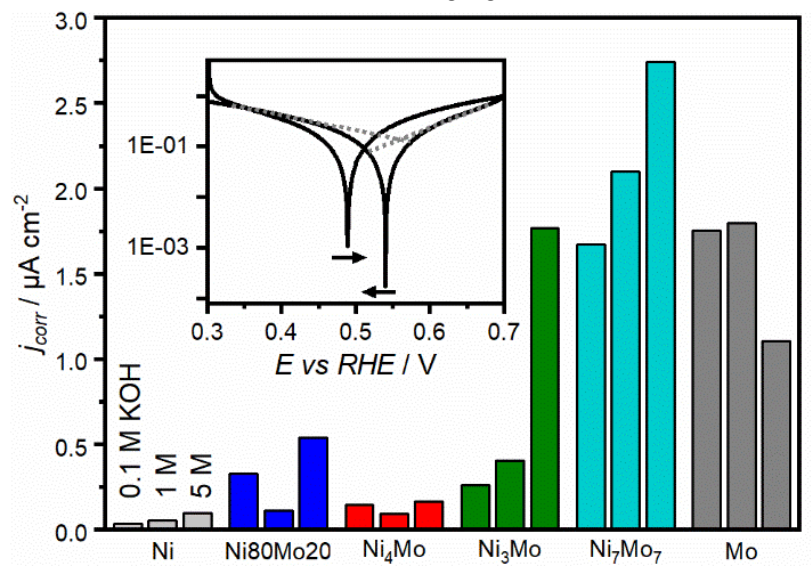

Figure 3. Corrosion current densities of the planar electrodes in different $\mathrm{KOH}$ concentrations. The inset shows Tafel plots of an exemplary measurement on $\mathrm{Ni}_{4} \mathrm{Mo}$ in $0.1 \mathrm{M} \mathrm{KOH}$ and $d E / d t=$ $0.5 \mathrm{mVs}^{-1}$.

A trend of $j_{c o r r}$ increasing with the $\mathrm{pH}$ value and the molybdenum content is apparent. This can be understood on the basis of Pourbaix diagrams of $\mathrm{Ni}$ and Mo. While nickel forms a passivating layer of $\mathrm{NiO} / \mathrm{Ni}(\mathrm{OH})_{2}$ in alkaline media ${ }^{[43]}$ molybdenum is not passivating but undergoes a steady dissolution to form divalent molybdate ions ${ }^{[44]}$.

From the investigations, the passivation of Mo-Ni electrodes is depending on Mo-content and $\mathrm{pH}$. While electrodes containing 20 at. $\%$ molybdenum are passivating up to $5 \mathrm{M} \mathrm{KOH}, \mathrm{Ni}_{3} \mathrm{Mo}$ is steadily decomposing in $\mathrm{KOH}$ concentrations above $1 \mathrm{M}$, as $j_{\text {corr }}$ is comparable to elemental molybdenum. The latter holds true for $\mathrm{Ni}_{7} \mathrm{Mo}_{7}$ in all investigated electrolytes. Surprisingly, a higher $j_{\text {corr }}$ is observed on Ni80Mo20 and $\mathrm{Ni}_{4} \mathrm{Mo}$ in $0.1 \mathrm{M} \mathrm{KOH}$ as compared to $1 \mathrm{M} \mathrm{KOH}$. This can be explained by molybdenum dissolution contributing in the first measurement, while a molybdenum depleted surface is investigated in the $1 \mathrm{M} \mathrm{KOH}$ solution. Nickelrich Mo-Ni materials thus resemble the passivating behavior of elemental nickel after a certain time of exposure to $\mathrm{KOH}$ concentrations up to $1 \mathrm{M}$.

Further confirmation for the preferential surface depletion of molybdenum and the resulting passivation can be found in CV scans between 0.0 and $1.6 \mathrm{~V}$ vs RHE (Fig. 4). Characteristic redox signals of nickel served exclusively as basis for the judgement of a nickel-terminated surface layer. On elemental nickel five signals ( $A$ to $E$ ) are observed in the potential range of $0-1.6 \mathrm{~V}$ vs RHE. The oxidation of $\mathrm{Ni}(\mathrm{OH})_{2}$ to $\mathrm{NiOOH}$ causes two $C V$ signals ( $A$ and $B$ ) in the forward scan, as the oxidation potential depends upon the water content in the hydroxides. ${ }^{[4-48]}$ Signal $(C)$ is assigned to the oxygen evolution reaction. In the backward scan, a broad signal (D) and a sharp signal (E) are observed. Both are assigned to the reduction of either different $\mathrm{NiOOH}$ modifications ${ }^{[48]}$ or different thicknesses of a single modification, i.e. $\beta-\mathrm{NiOOH}^{[46]}$.

CV measurements on nickel-rich Mo-Ni surfaces show increased current densities below $1.3 \mathrm{~V}$ within the first cycle in comparison to elemental nickel, which is assigned to the dissolution of Mo from the surface. In addition, the oxidation signal (B) is pronounced in samples containing molybdenum. After the first three cycles, the typical reversible behavior of nickel is retained. This indicates a surface state, which is very similar to elemental nickel, thus corroborating the passivation behavior observed in the corrosion studies. The $\mathrm{CVs}$ on $\mathrm{Ni}_{7} \mathrm{Mo}_{7}$ do not stabilize within 24 cycles, showing current densities two orders of magnitude higher than on all other materials. Characteristic signals of nickel redox-processes were not distinguishable, due to an overlap within the strong signals of molybdenum oxidation above $850 \mathrm{mV}{ }^{[49]}$ These findings are in line with the corrosion studies and indicate a dissolution of molybdenum from $\mathrm{Ni}_{7} \mathrm{Mo}_{7}$ within this potential regime.

The first cycle on freshly polished Mo-Ni electrodes (Figure 4), shows signals attributable to Mo-dissolution. After the mild ADT, exclusively nickel-related redox-signals were observed in the first cycle (Figure 5a), suggesting that molybdenum was dissolved from the surface during the mild ADT. The additional oxidation process at $\sim 350 \mathrm{mV}(\mathrm{Z})$, which was not detected in the polished state, is assigned to the oxidation of $\mathrm{Ni}$ to $\alpha-\mathrm{Ni}(\mathrm{OH})_{2}$, while the constant anodic current density between $(\mathrm{Z})$ and $(\mathrm{A})$ 
indicates thickening and ageing of the $\alpha-\mathrm{Ni}(\mathrm{OH})_{2}$ to the $\beta$ modification. ${ }^{[47]}$

Different extents of molybdenum leaching caused by the ADTs might have an influence on the exposed surface area in contact with the electrolyte. This would result in altered geometric current densities, even though the intrinsic activity does not change. Thus, the electrochemically active surface area (ECSA) needs to be determined. The ECSA is here based on the transferred charge in the reduction process of $\mathrm{NiOOH}$ between 1.2 and $1.5 \mathrm{~V}$ vs RHE:

$\mathrm{NiOOH}+e^{-}+\mathrm{H}_{2} \mathrm{O} \leftrightharpoons \mathrm{Ni}(\mathrm{OH})_{2}+\mathrm{OH}^{-}$

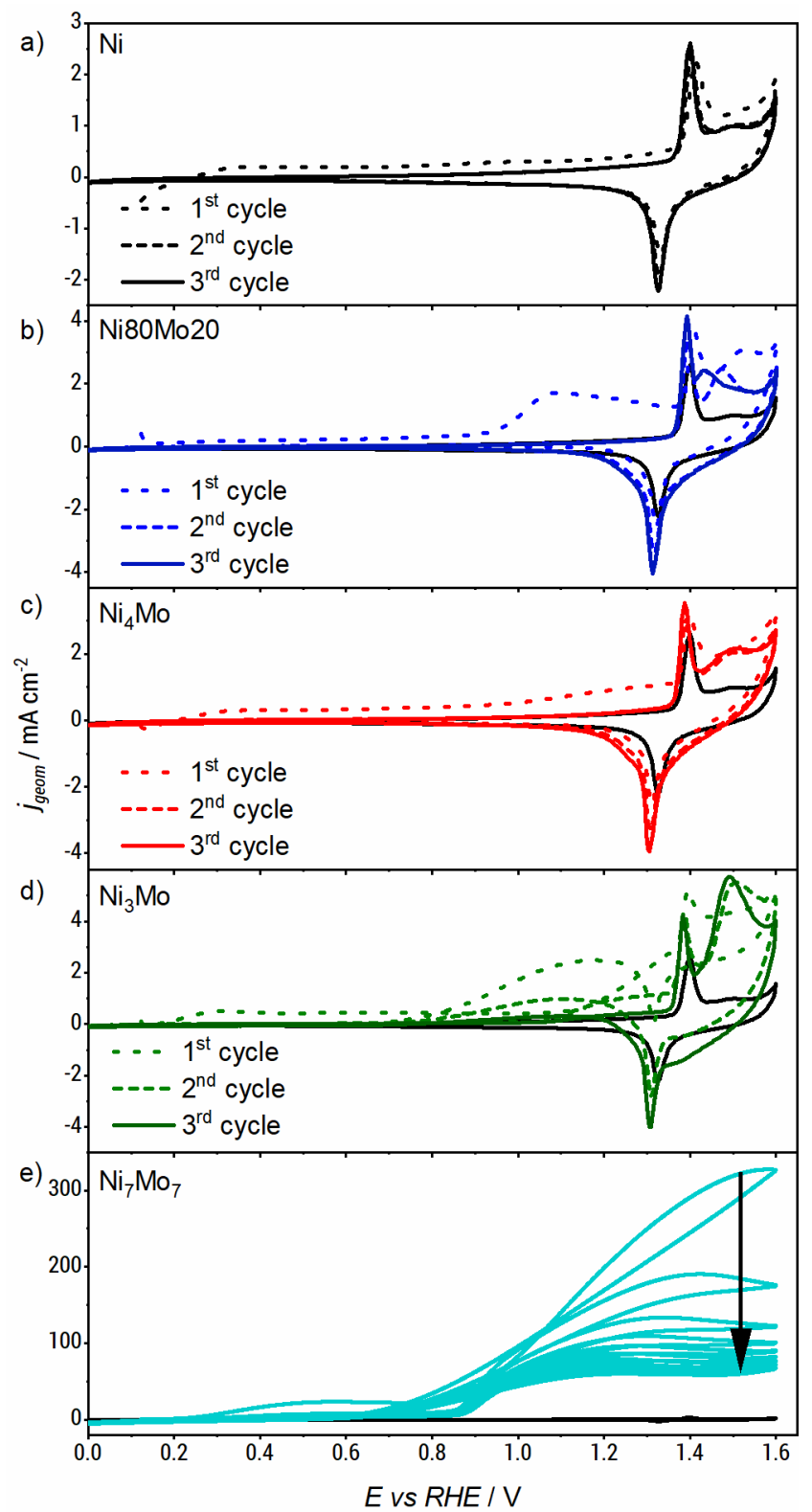

Figure 4. $\mathrm{CV}$ cycles of the electrodes in a freshly polished state in $1 \mathrm{M} \mathrm{KOH}, 200 \mathrm{mV} / \mathrm{s}$. For comparison, the $3^{\text {rd }}$ cycle of elemental nickel is added to all Mo-Ni panels. Letters A-E indicate different redox-processes as described within the text.

Scanning Mo-Ni materials repetitively to potentials of $1.6 \mathrm{~V}$ results in molybdenum dissolution, which might increase the ECSA and enrich the surface with nickel. ${ }^{[22]}$ To determine the changes quantitatively, the ESCA was calculated using Equation 1.

$$
\mathrm{A}_{\mathrm{ECSA}}=\frac{\mathrm{QN}_{\mathrm{A}}}{\mathrm{N}_{-}} \mathrm{k}_{\text {mean }} \quad \text { Equation } 1
$$

$Q$ is the integrated charge, $N_{A}$ Avogadro's number, $F$ the Faraday constant, $n$ the number of transferred electrons and $k_{\text {mean }}$ the mean area of a $\beta-\mathrm{NiOOH}$ unit cell assuming a statistical orientation (details are given in the SI). Relating the ESCA and the geometric surface area a roughness factor $R_{f}$ can be derived (Eq. 2).

$$
R_{f}=\frac{A_{E C S A}}{A} \quad \text { Equation } 2
$$

The roughness factors of the polished electrodes and after the mild ADT protocol are compared in Figure 5b. A comparison to Schalenbach et al. ${ }^{[25]}$ shows that the values are reasonable where a $R_{f}$ of $\sim 2$ was determined on a polished $\mathrm{Ni}$ electrode. The Mo-Ni materials in this study have roughness factors between three and four. As the polishing procedure is identical on all electrodes, the higher $R_{f}$ is related to molybdenum leaching during the ECSA determination, i.e. cycling three times to $1.6 \mathrm{~V}$. The mild ADT protocol does not seem to change the surface area significantly.

After 700 cycles the ECSA normalized current densities converge towards approximately $-1.35 \mathrm{~mA} \mathrm{~cm}^{-2}$ at an overpotential of $350 \mathrm{mV}$, irrespective of the used electrode. This suggests that the final surface state, at least for the electrodes with Mo contents $\geq 25$ at. $-\%$, are rather similar after the mild ADT. 

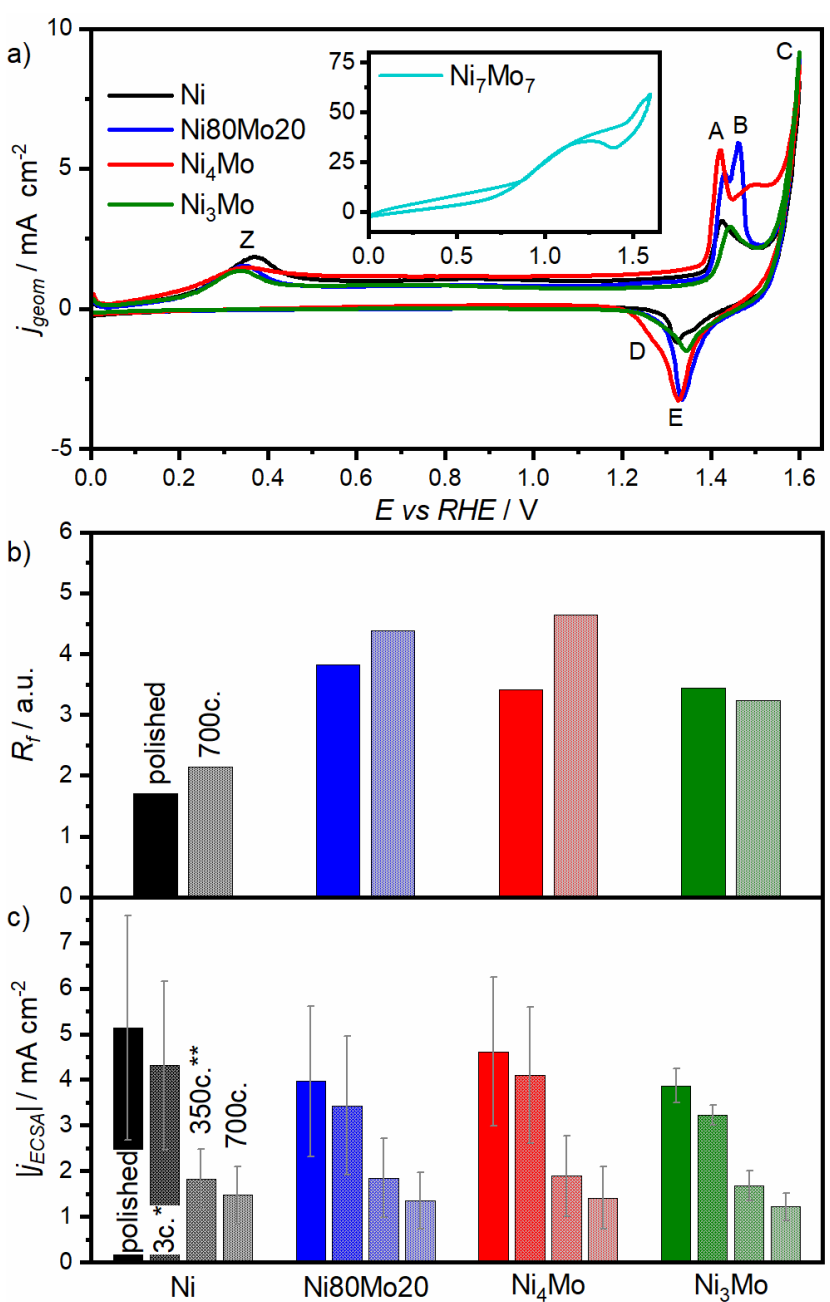

Figure 5. First $\mathrm{CV}$ cycle of the respective electrodes after the mild ADT $\left(E_{\text {upp }}=0.0 \mathrm{~V}\right.$ ) in $1 \mathrm{M} \mathrm{KOH}, 200 \mathrm{mV} / \mathrm{s}$ (a). Roughness factors (b) and ECSA normalized current densities at an overpotential of $350 \mathrm{mV}$ (c) for the individual electrode materials. The area for current normalization of the third and $350^{\text {th }}$ cycle was taken from the ECSA-determinations of the polished state $\left({ }^{*}\right)$ and the state after 700 cycles $\left({ }^{\star *}\right)$, respectively.

The CV cycles, roughness factors and ECSA normalized current densities of the electrodes treated in the harsh ADT protocol $\left(E_{\text {upp }}=0.4 \mathrm{~V}\right.$ vs RHE) are displayed in Figure 6. As expected from the corroded surfaces, the charge below the individual nickel-redox signals is higher than in the polished state. This behavior is not different from the alloys and multi-phase samples investigated by Schalenbach et al. ${ }^{[25]}$, suggesting a complete dissolution of all molybdenum from the electrodes surface, making the Mo-Ni compounds precursors for high specific-surface area nickel catalysts.

Also after the harsh test, $\mathrm{Ni}_{7} \mathrm{Mo}_{7}$ does not show reversible redoxbehavior (Fig. 6a). Nevertheless, a distinction of characteristic nickel signals is now possible and the maximum current density achieved for $\mathrm{Ni}_{7} \mathrm{Mo}_{7}$ after the harsh $\mathrm{ADT}$ is only $25 \%$ of the polished state. It is thus likely that the majority of molybdenum is dissolved from the surface, which would also explain the observed surface discoloration.
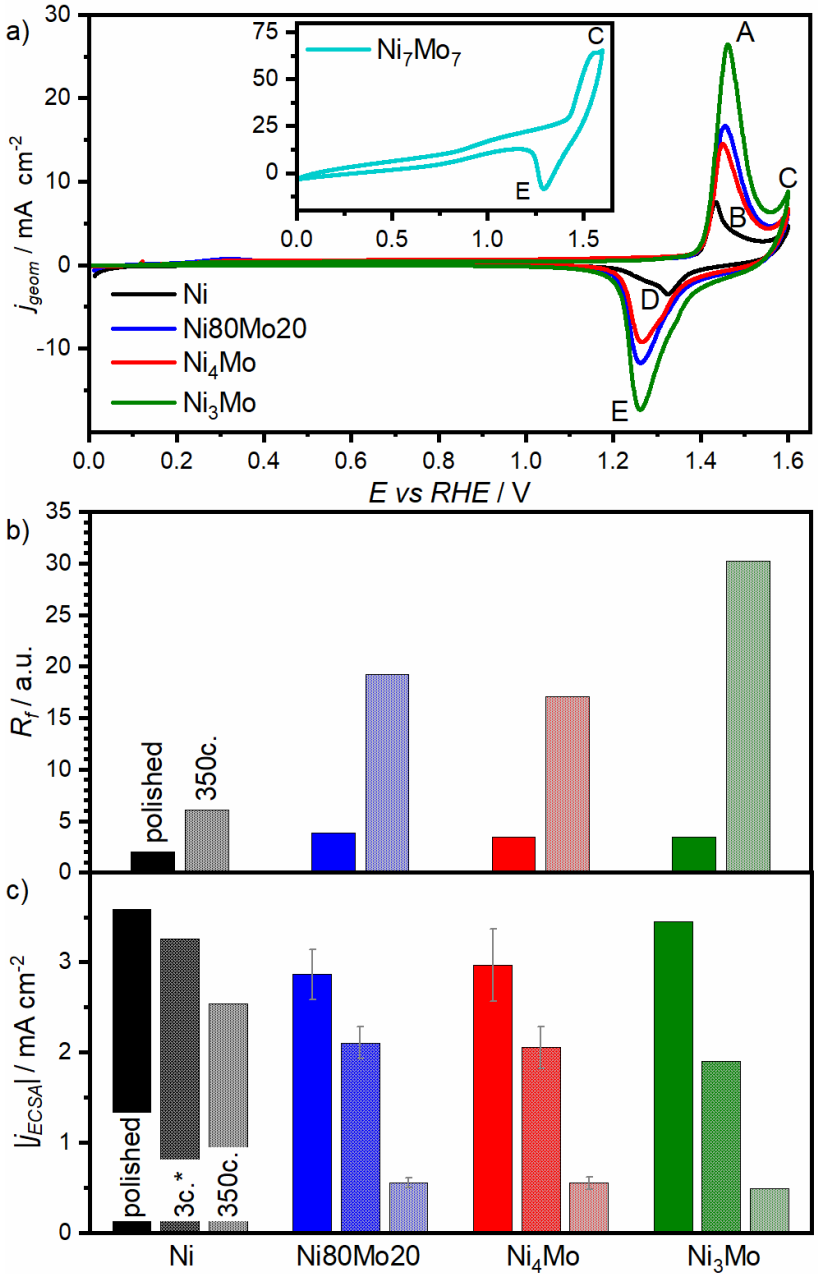

Figure 6 First $\mathrm{CV}$ cycle of the respective electrodes after the harsh $\mathrm{ADT}\left(E_{\text {upp }}=0.4 \mathrm{~V}\right)$ in $1 \mathrm{M} \mathrm{KOH}, 200 \mathrm{mV} / \mathrm{s}$. (a). Roughness factors (b) and ECSA normalized current densities at an overpotential of $350 \mathrm{mV}$ (c) for the individual electrodes materials. The area for current normalization of the third cycle was taken from the ECSA-determinations of the polished state $\left({ }^{*}\right)$.

The calculated roughness factors $\left(R_{t}\right)$ before and after the harsh protocol are displayed in Figure 6b. While the surface roughness for elemental $\mathrm{Ni}$ increases by a factor of $\sim 3$ within the harsh ADT, the increase-factor for Ni80Mo20 and $\mathrm{Ni}_{4} \mathrm{Mo}$ is $\sim 4$ and $\sim 7$ in the case of $\mathrm{Ni}_{3} \mathrm{Mo}$. The obtained ECSA specific current densities offer a clear picture of the activity changes during the ADT. Molybdenum-containing samples deactivate much stronger than an elemental nickel electrode. Pseudo-stable behavior which could be concluded from Figure S2 has thus to be interpreted as a balance between an increase in electrochemical surface area and a decrease in ECSA specific activity.

In comparison to the mild ADT protocol (Figs. 2 and 5), nickel retains a higher current density after 350 cycles in the harsh ADT, while Mo-Ni electrodes deactivate even more. This might be related to a known deactivation mechanism of nickel electrodes in the HER, i.e. bulk-hydride formation. ${ }^{[14,47]} \mathrm{Mo}-\mathrm{Ni}$ materials cannot absorb hydrogen due to the trapping of hydride on molybdenum sites in the near-surface region ${ }^{[50]}$. While the oxidative removal of $\mathrm{Ni}-\mathrm{H}$ is possible in the harsh protocol by applying potentials above $0 \mathrm{~V}$, the mild protocol operating in the HER regime does not allow for this "cleansing" of elemental nickel, resulting in a decreasing activity ${ }^{[51]}$. 


\section{Ex situ Characterization}

To quantify the dissolution and explore the deactivation of Mo-Ni materials during HER, electrodes pretreated by the mild ADT protocol and their respective electrolytes were characterized ex situ. Results from the elemental analysis of the electrolytes after the mild ADT are shown in Table 1. The concentrations are normalized against the exposed geometric surface area of the individual electrodes.

Table 1. Surface-normalized ionic concentrations in the electrolytes (in $\mu \mathrm{gL}^{-1} \mathrm{~cm}^{-2}$ ) after the mild ADT.

\begin{tabular}{llllll}
\hline material & $\mathrm{Ni}$ & $\mathrm{Ni80Mo20}$ & $\mathrm{Ni} 4 \mathrm{Mo}$ & $\mathrm{Ni} 3 \mathrm{Mo}$ & $\mathrm{Ni} 7 \mathrm{Mo}_{7}$ \\
\hline molybdenum & - & 125 & 235 & 80 & 27890 \\
nickel & 551 & 371 & 111 & 275 & 190 \\
\hline
\end{tabular}

The passivating behavior of nickel-rich Mo-Ni electrodes in $1 \mathrm{M} \mathrm{KOH}$ at potentials below $0 \mathrm{~V}$ vs $\mathrm{RHE}$ is confirmed by the nickel dissolution being of the same order of magnitude as for elemental nickel. In contrast, $\mathrm{Ni}_{7} \mathrm{Mo}_{7}$ suffered from severe preferential dissolution of molybdenum, establishing its instability under HER conditions.

Ex situ XP-spectra proof that the (inter-)metallic species are still in the same chemical state as in the reference state (Fig. 7). The most significant change for all molybdenum containing samples is the higher ratio of the $\mathrm{Ni}(\mathrm{OH})_{2} / \mathrm{Ni}$ signals. In the case of $\mathrm{Ni}_{7} \mathrm{Mo}_{7}$, the latter vanished completely, and the near-surface region contains the highest content of oxidized molybdenum species of all Mo-Ni samples.

Exploiting the observation that metallic species are detectable on all electrodes after the mild ADT (i.e. the information depth comprises the whole oxidized region) and assuming that the surface oxidation occurs layer by layer, a relative compositional analysis of the near-surface region in the as-polished and the ex situ state is possible (Figure 7c). The relative abundance of different Mo-species does not significantly change for $\mathrm{Ni}$-rich samples, thus underlining the passivating behavior of $\mathrm{NiOOH}$ as concluded from CVs and corrosion studies. In the case of $\mathrm{Ni}_{7} \mathrm{Mo}_{7}$, the mild ADT leads to a higher content of oxidized molybdenum. In agreement with the intensities obtained by fitting the O1s spectra (Fig. S3), the oxidized Mo-species might be assigned to $\mathrm{MoO}_{2}$ for $\mathrm{Mo}^{4+}$ and $\mathrm{MoO}_{3}$ for $\mathrm{Mo}^{6+}$ and $\mathrm{Mo}^{5+}$, where the latter results from reduction of $\mathrm{Mo}^{6+}$ by $\mathrm{X}$-ray irradiation in ultra-high vacuum. ${ }^{[40]}$
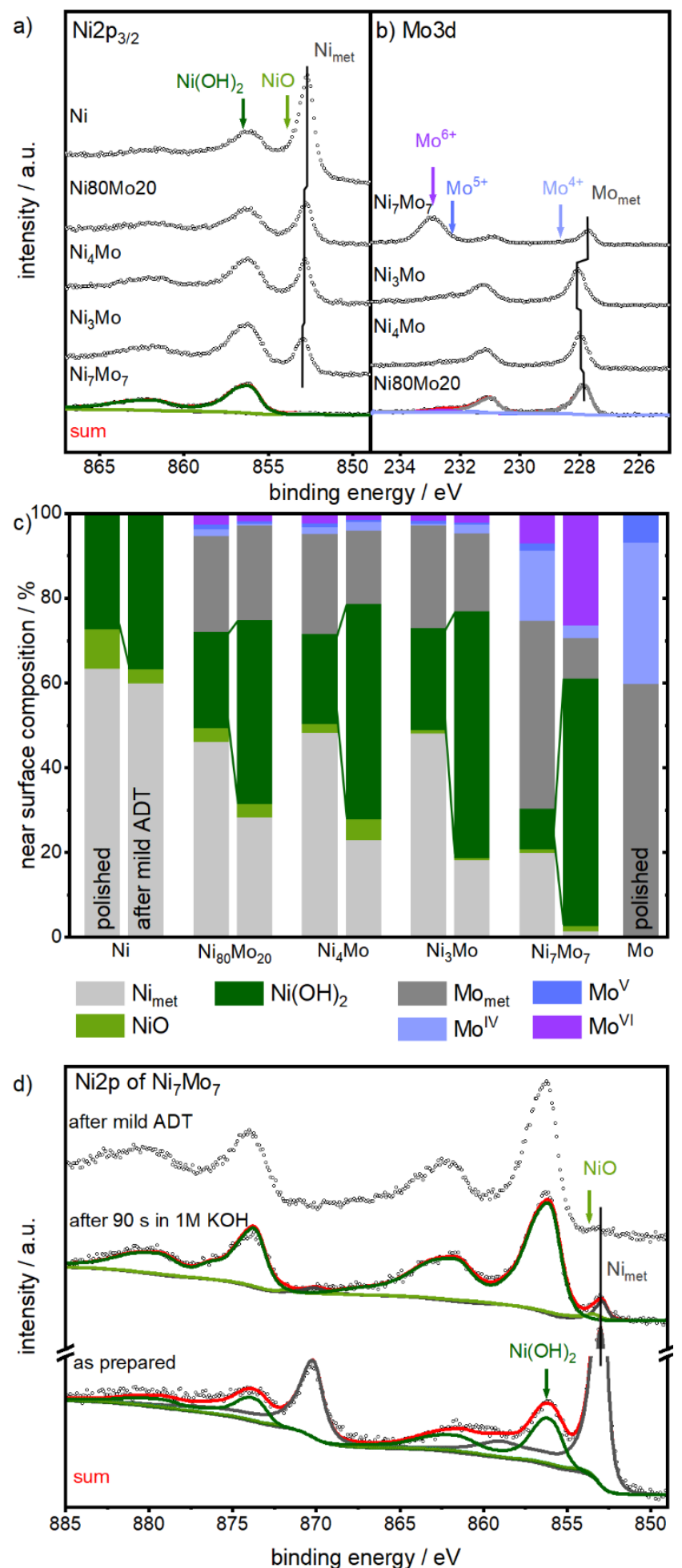

Figure 7. Ex situ XP spectra in the $\mathrm{Ni}_{2} \mathrm{p}_{3 / 2}$ (a) and Mo3d (b) region obtained after the mild ADT. Quantitative near-surface composition of the individual elements in the polished state and after the mild $A D T$ (c). Ni2p spectral region of $\mathrm{Ni}_{7} \mathrm{Mo}_{7}$ after different pretreatments $(d)$.

Recent studies related high activities of Mo-Ni materials to water activating properties of molybdenum oxides, thus enabling a bifunctional HER mechanism. ${ }^{[29,30]}$ Activity enhancements unrelated to higher surface areas were not observed on nickel-rich single-phase Mo-Ni materials in this study. CV cycles after the 
mild ADT did not show molybdenum-related signals and the relative composition of the near-surface region contains less molybdenum after the mild ADT. An exemplary measurement of $\mathrm{Ni}_{4} \mathrm{Mo}$ pretreated in the harsh ADT did not show any signals in the Mo3d region (Fig. S4). The highest molybdenum loss was observed on $\mathrm{Ni}_{7} \mathrm{Mo}_{7}$ as expected from elemental analysis. Thus, molybdenum oxides seem just to be intermediates on the way to molybdenum species in solution. This conclusion is supported by the corrosion studies and in agreement with the Pourbaix diagram ${ }^{[4]}$. Due to the intermediate nature of $\mathrm{MoO}_{x}$, a potential bifunctional mechanism involving ( $\mathrm{Mo}-) \mathrm{Ni} / \mathrm{MoO}_{x}$, even though it cannot be excluded, would be of a rather short lived nature.

Focusing on the nickel species, the near-surface region of the elemental nickel electrode underwent only a slight oxidation forming $\mathrm{Ni}(\mathrm{OH})_{2}$. On nickel-rich Mo-Ni electrodes the relative ratio of metallic to hydroxidic nickel, being approximately $2: 1$ in the polished state is inverted after the mild ADT. Thus, it is concluded that molybdenum addition increases the corrosion sensitivity of nickel. This destabilization might be due to the partial electron transfer of nickel towards molybdenum (electronic effect), resulting in a higher electrophilicity of nickel, thus a higher likeliness to react with $\mathrm{OH}^{-}$in alkaline media. In addition, the highly defective surface left behind by the dissolution of molybdenum would be more prone to oxidation.

Comparing the results on the Ni80Mo20 solid solution and the ordered intermetallic compound $\mathrm{Ni}_{4} \mathrm{Mo}$, allows to explore the influence of the ordered crystal structure. XPS reveals no significant differences in the chemical state. However, the crystal structure of $\mathrm{Ni}_{4} \mathrm{Mo}$ below an XRD-amorphous $\mathrm{Ni}(\mathrm{OH})_{2}$ layer remains intact within a probed depth of $\sim 27 \mathrm{~nm}$ ( $\sim 80$ unit cells) as no other reflections could be detected by a grazing incidence X-ray diffraction (GI-XRD) measurement (Fig. S5). As the different underlying crystal structure does not result in a different HER activity, a structural influence of the intermetallic compound is negligible for Mo-Ni samples having Mo-contents of 20 at.-\%. As intermetallic compounds containing more molybdenum are even more sensitive to oxidation of the near-surface region, an influence of their crystal structures to the HER activity is even less likely. This leads to the conclusion, that intermetallic Mo-Ni compounds are merely precursors for $\mathrm{Ni}(\mathrm{OH})_{2}$ terminated electrocatalysts in alkaline solutions under the applied conditions.

To test the stated superior stability ${ }^{[28,52]}$ of $\mathrm{Ni}_{7} \mathrm{Mo}_{7}$, freshly cracked surfaces were immersed in $1 \mathrm{M} \mathrm{KOH}$ for $90 \mathrm{~s}$. This is the approximate time of electrolyte contact before a measurement was started. The treatment is sufficient to oxidize most of the metallic nickel within the near-surface region of the sample to $\mathrm{Ni}(\mathrm{OH})_{2}$ as shown by XPS (Fig. $7 \mathrm{~d}$ ). The line shape of the respective Ni2p region is almost identical to the state after the mild ADT, indicating the surface to be in a very similar chemical state. This suggests the "durability" and "higher activity" of $\mathrm{Ni}_{7} \mathrm{Mo}_{7}$ compared to the other samples is a result of its very fast decomposition in $1 \mathrm{M} \mathrm{KOH}$, leading to a high surface area $\mathrm{Ni}(\mathrm{OH})_{2}$ catalyst.

To further underline the completely different behavior of $\mathrm{Ni}_{7} \mathrm{Mo}_{7}$ in comparison to nickel-rich Mo-Ni materials and elemental nickel, chronopotentiometric measurements were conducted at a current density of $-100 \mathrm{~mA} / \mathrm{cm}^{2}$ (Fig. 8). While $\mathrm{Ni}_{7} \mathrm{Mo}_{7}$ directly started at an overpotential above $650 \mathrm{mV}$, the nickel-rich materials were more active with $\eta=450 \mathrm{mV}$. Based on the aforementioned findings, this corresponds to $\mathrm{Ni}_{7} \mathrm{Mo}_{7}$, which is completely covered in Ni-hydroxide when the measurement begins. It is thus less active than the other samples, which are still in part (inter-)metallic. The high overvoltage of the equimolar compound decreases within $16 \mathrm{~h}$ due to steady Mo-dissolution, leading to an increased surface area in contact with the electrolyte. This corrosion-induced surface roughening does not happen on passivating nickel-rich materials. Based on the XPS results, their increasing overvoltage is a consequence of oxidation of the near-surface region and/or hydride formation in the case of elemental nickel.

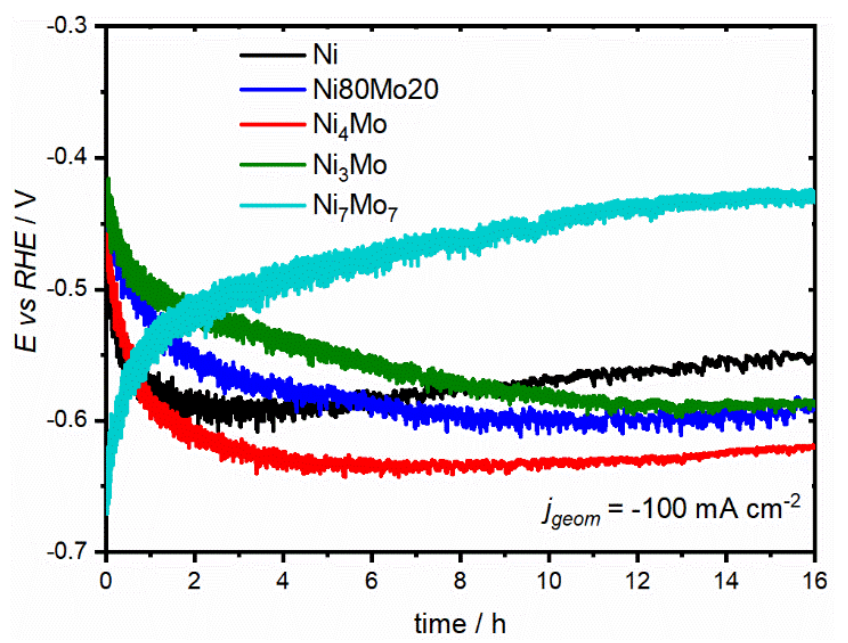

Figure 8 Chronopotentiometry at a fixed current density of $-100 \mathrm{~mA} / \mathrm{cm}^{2}$ in $1 \mathrm{M} \mathrm{KOH}$ solution.

Bringing this conclusion from bulk $\mathrm{Ni}_{7} \mathrm{Mo}_{7}$ in line with recent results of very durable nanoparticulate Mo-Ni catalysts, it is likely that their "durability" is the result of extremely fast decomposition in the reaction media.

\section{Conclusion}

The single-phase intermetallic compounds $\mathrm{Ni}_{4} \mathrm{Mo}, \mathrm{Ni}_{3} \mathrm{Mo}$ and $\mathrm{Ni}_{7} \mathrm{Mo}_{7}$ were synthesized as bulk-materials and investigated by two different ADT protocols along with elemental nickel and the substitutional alloy Ni80Mo20. In alkaline media and upper reverse potentials of $+0.4 \mathrm{~V}$ vs $\mathrm{RHE}$, the Mo-Ni materials corroded due to preferential dissolution of molybdenum, leading to increased specific surface areas. Except for $\mathrm{Ni}_{7} \mathrm{Mo}_{7}$, this did not happen when the potential limit was restricted to $0.0 \mathrm{~V}$ vs RHE. Irrespective of the applied protocols, the ECSA-specific HER current densities decreased during the ADTs. This change of activity is related to the composition of the near-surface region obtaining a higher $\mathrm{Ni}(\mathrm{OH})_{2}$ content with respect to the reference state. An influence of the ordered crystal structure of intermetallic compounds on the HER activity could not be observed.

\section{Experimental Section}

The intermetallic compounds $\mathrm{Ni}_{3} \mathrm{Mo}, \mathrm{Ni}_{4} \mathrm{Mo}$ and the substitutional alloy Ni80Mo20 were prepared by arc melting of stoichiometric amounts of nickel pellets (6 mm, ChemPUR, 99.995\%, Co $<10$ ppm) and molybdenum foil $(0.025 \mathrm{~mm}$, Alfa Aesar, 99.95\%) in an argon-filled glovebox $\left(\mathrm{O}_{2}\right.$ and $\mathrm{H}_{2} \mathrm{O}$ below $\left.0.1 \mathrm{ppm}\right)$. All samples were homogenized by remelting the samples three times, then pressed flat with a hydraulic press at 12 kbar. To obtain the ordered intermetallic compounds, the samples were annealed in evacuated quartz-glass ampoules for $14 \mathrm{~d}$ at $890^{\circ} \mathrm{C}$ 
and $45 \mathrm{~d}$ at $750{ }^{\circ} \mathrm{C}$ for $\mathrm{Ni}_{3} \mathrm{Mo}$ and $\mathrm{Ni}_{4} \mathrm{Mo}$, respectively, then quenched in brine to ambient temperature. For the synthesis of $\mathrm{Ni}_{7} \mathrm{Mo}_{7}$, nickel (powder $<10 \mu \mathrm{m}$, ChemPUR, 99\%) and molybdenum (powder 2-5 $\mu \mathrm{m}$, ChemPUR, $99.95 \%$ ) were mixed in a 47:53 ratio and pressed to a pill at $12 \mathrm{kbar}$ in a hydraulic press. In a glovebox, the pill was placed in a corundum crucible along with $15 \mathrm{mg}$ of iodine, then transferred into a quartz-glass ampoule. The ampoule was sealed under static vacuum and constant cooling, then placed in an oven for $14 \mathrm{~d}$ at $1000^{\circ} \mathrm{C}$. After quenching, the pill was crushed to powder, then compacted by spark-plasma-sintering. Therefor powders were put into a dye $(d=8.1 \mathrm{~mm})$, compacted by a pressure of 400-500 bar and heated up to $1000{ }^{\circ} \mathrm{C}$ at a heating rate of $\sim 100 \mathrm{~K} / \mathrm{min}$ (pulsed DC current). The choices of encapsulation materials were not ideal. While the common choice of carbon dyes and -foils leads to the formation of $\mathrm{MoC}_{2}$, the usage of Mo-foils leads to an enrichment of the molybdenum content of the sintered materials. To minimize this influence, a trade-off of sample compaction and molybdenum intrusion into the sample needed to be found. Thus, the reaction time was decreased to a minimum and the $\mathrm{Ni}_{7} \mathrm{Mo}_{7}$ powders were only heated up to $1000{ }^{\circ} \mathrm{C}$ and cooled down to ambient temperature directly afterwards. Before further usage, the as-obtained SPS-pills were sanded with P800 SiC grinding paper from all sides to remove potential Mo-enriched material.

All samples were embedded with an electric contact to the rear in a PMMA-based resin (Technovit 5071, Heraeus-Kulzer). Then grinded (SiC-paper) and polished (diamond-suspension) to a finish of $0.125 \mu \mathrm{m}$. The pores of the $\mathrm{Ni}_{7} \mathrm{Mo}_{7}$ sample were closed off by covering a prepolished surface with a thin layer of two-component resin (UHUSchnellfest). The hardened resin was carefully removed by polishing, resulting in a flat surface of intermetallic compound and resin domains.

Sample characterization was done on the embedded electrodes in the same state as they were subjected to the electrochemical experiments. Phase analysis was conducted by XRD in reflection mode (Enraf Nonius, Inel CPS120 detector, $\mathrm{Cu} K \mathrm{Ka}_{1}$ radiation $\lambda=1.54056 \AA$, Ge (111) monochromator, range $7^{\circ}<2 \theta<113^{\circ}$ ), light- (Zeiss, Axioscope A1) and electronmicroscopy (Philips, XL30). Gl-XRD measurements were conducted in reflection mode with an incident angle of $\omega=0.42^{\circ}$ (Smartlab Studio II, Rigaku, $4.5 \mathrm{~kW}$ rotating anode, Cu Ka radiation, nickel filter). For XPS measurements, the electrode cylinders were cut to a height of $10 \mathrm{~mm}$, evacuated overnight, then transferred into the high-vacuum chamber of the XPS device (SPECS-spectrometer, X-ray source: XR50m, FOCUS 500 monochromator (adjusted for Al-Ka, hv $=1486.7 \mathrm{eV}$, PHOIBOS 150 MCD-9 hemispherical analyser, chamber pressure $p<3 \times 10^{-10}$ mbar, photoelectron take-off angle: $45^{\circ}$ ). Fitting constraints of XP-spectra and relative quantification details are given in the Supporting Information.

Elemental analysis of the samples and electrolytes after the ADT was conducted by ICP-OES against a matrix-calibrated standard (Agilent, ICP-OES 715, radial torch). A fraction of the sample was dissolved in aqua regia, diluted with distilled deionized water and acidified with $\mathrm{HCl}$ before analysis.

The electrochemical experiments were conducted in an in-house built one-compartment electrochemical cell, using quartz-glass and Teflon as building materials. Perfluorinated sealing rings were used to seal the cell. The working electrode was placed in the bottom of the cell. For the reference electrode, $\mathrm{Hg} / \mathrm{HgO}$ (BasInc) or a reversible hydrogen electrode (RHE, Hydroflex, Gaskatel) was used. All the potentials are reported with reference to the RHE. A platinum gauze $\left(2.5 \mathrm{~cm}^{2}\right)$ served as counter electrode. Experiments were conducted at ambient temperature in unstirred $30 \mathrm{~mL}$ of freshly prepared $\mathrm{KOH}$-solutions. All electrolytes were prepared by dissolving potassium hydroxide (Grüssing, puriss. water content $15 \%$ ) in ultrapure water (Millipore, $18.2 \mathrm{M} \Omega \mathrm{cm}$. Prior to the measurements, the electrolyte was purged with argon $(99.999 \%$, Air Liquide) for 20 minutes with around $50 \mathrm{ml} / \mathrm{min}$ to remove dissolved oxygen and a dynamic argon atmosphere was maintained above the electrolyte during the electrochemical experiments.
Corrosion studies were conducted by measuring the OCP for 20 minutes, then applying a forward- and backward linear voltammetry scan around $\pm 200 \mathrm{mV}$ vs OCP with a sweep rate of $0.5 \mathrm{mV} / \mathrm{s}$. The corrosion current density was calculated from the individual corrosion current densities as obtained by extrapolated intersections of the linear cathodic and anodic branches ofthe Tafel plots. The ADT protocols were adapted from Schalenbach et al. ${ }^{[25]}$ and are briefly described in the following. The ADTs are composed of alternating sequences. The first is used for the activity determination after different ADT cycles and is composed out of three cycles between $0.0(0.1 \mathrm{~V}$ for the harsh ADT) and $-0.4 \mathrm{~V}$ vs RHE at a scan rate of $d E / d t=10 \mathrm{mV} \mathrm{s}^{-1}$. The positive sweep of the third cycle is reported. The ADT cycles were conducted between $0.0(0.4 \mathrm{~V}$ for the harsh ADT) and $-0.4 \mathrm{~V}$ vs RHE at a scan rate of $200 \mathrm{mV} \mathrm{s}^{-1}$. The activity is reported in the polished state, after three, 350 and 700 ADT cycles. The chronopotentiometric measurement was conducted at a current density of $-100 \mathrm{~mA} \mathrm{~cm}^{-2}$.

\section{Acknowledgements}

LR gratefully acknowledges the European Social Funds for his PhD scholarship (Project No 100284169). RZ thanks the German Academic Exchange Service (DAAD) for his PhD grant.

Keywords: intermetallic compound $\bullet$ hydrogen evolution $\bullet$ nickel - molybdenum $\cdot \mathrm{MoNi}_{4} \cdot \mathrm{MoNi}_{3} \cdot \mathrm{Mo}_{7} \mathrm{Ni}_{7}$

[1] A. Midilli, I. Dincer, M. Ay, Energy Policy 2006, 34, 36233633.

[2] M. Ball, M. Wietschel, Int. J. Hydrogen Energy 2009, 34, 615-627.

[3] B. Dunn, H. Kamath, J.-M. Tarascon, Science 2011, 334, 928-935.

[4] T. E. Mallouk, Nat. Chem. 2013, 5, 362-363.

[5] G. W. Crabtree, M. S. Dresselhaus, M. V. Buchanan, World Futur. Soc. Conf. Hyatt Gd. Hotel. Washington, DC, July 2004, 57, 39-44

[6] G. A. Olah, G. K. S. Prakash, A. Goeppert, J. Am. Chem Soc. 2011, 133, 12881-12898.

[7] P. C. K. Vesborg, B. Seger, I. Chorkendorff, J. Phys. Chem Lett. 2015, 6, 951-957.

[8] C. C. L. McCrory, S. Jung, I. M. Ferrer, S. M. Chatman, J. C. Peters, T. F. Jaramillo, J. Am. Chem. Soc. 2015, 137, 4347-4357.

[9] M. Carmo, D. L. Fritz, J. Mergel, D. Stolten, Int. J. Hydrogen Energy 2013, 38, 4901-4934.

[10] P. C. K. Vesborg, T. F. Jaramillo, RSC Adv. 2012, 2, 79337947.

[11] J. Zhang, T. Wang, P. Liu, Z. Liao, S. Liu, X. Zhuang, M. Chen, E. Zschech, X. Feng, Nat. Commun. 2017, 8, 15437.

[12] M. Schalenbach, G. Tjarks, M. Carmo, W. Lueke, M. Mueller, D. Stolten, J. Electrochem. Soc. 2016, 163, F3197-F3208.

[13] O. Schmidt, A. Gambhir, I. Staffell, A. Hawkes, J. Nelson, S. Few, Int. J. Hydrogen Energy 2017, 42, 30470-30492.

[14] K. Zeng, D. Zhang, Prog. Energy Combust. Sci. 2010, 36, 307-326.

[15] D. E. Brown, M. N. Mahmood, A. K. Turner, S. M. Hall, P. O. Fogarty, Int. J. Hydrogen Energy 1982, 7, 405-410.

[16] D. E. Brown, M. N. Mahmood, M. C. M. Man, A. K. Turner, Electrochim. Acta 1984, 29, 1551-1556.

[17] D. E. Brown, S. M. Hall, M. N. Mahmood, M. C. M. Man, A. K. Turner, D. Wood, S. Anderson, in Proc. Symp. Electrocatal. (Eds.: W.E. O'Grady, P.N. Ross, Jr., F.G. Will), The Electrochemical Society, Inc., New York, 1982, pp. 145-154.

[18] D. E. Brown, M. N. Mahmood, Method of Preparing Active Electrodes, 1982, US 4358475.

[19] D. E. Brown, M. N. Mahmood, Method of Stabilizing Electrodes Coated with Mixed Oxide Electrocatalysts during 
Use in Electrochemical Cells, 1984, US4426269.

[20] D. E. Brown, S. M. Hall, M. N. Mahmood, Electrodes and Method of Preparation Thereof for Use in Electrochemical Cells, 1982, US4342792A.

[21] N. Krstajic, V. Jovic, L. Gajickrstajic, B. Jovic, A. Antozzi, G. Martelli, Int. J. Hydrogen Energy 2008, 33, 3676-3687.

[22] J. H. J. Wijten, L. D. B. Mandemaker, T. C. van Eeden, J. E. Dubbeld, B. M. Weckhuysen, ChemSusChem 2020, 31723179.

[23] J. H. J. Wijten, R. L. Riemersma, J. Gauthier, L. D. B. Mandemaker, M. W. G. M. (Tiny. Verhoeven, J. P. Hofmann, K. Chan, B. M. Weckhuysen, ChemSusChem 2019, 12, 3491-3500.

[24] L. Rößner, M. Armbrüster, ACS Catal. 2019, 9, 2018-2062.

[25] M. Schalenbach, F. D. Speck, M. Ledendecker, O. Kasian, D. Goehl, A. M. Mingers, B. Breitbach, H. Springer, S. Cherevko, K. J. J. Mayrhofer, Electrochim. Acta 2018, 259, 1154-1161.

[26] M. R. Gennero de Chialvo, A. C. Chialvo, J. Electroanal. Chem. 1998, 448, 87-93.

[27] J. M. Jakšić, M. V. Vojnović, N. V. Krstajić, Electrochim. Acta 2000, 45, 4151-4158.

[28] M. Fang, W. Gao, G. Dong, Z. Xia, S. P. Yip, Y. Qin, Y. Qu, J. C. Ho, Nano Energy 2016, 27, 247-254.

[29] S. Deng, X. Liu, T. Huang, T. Zhao, Y. Lu, J. Cheng, T. Shen, J. Liang, D. Wang, Electrochim. Acta 2019, 324, 134892.

[30] D. Wang, C. Han, Z. Xing, Q. Li, X. Yang, J. Mater. Chem. A 2018, 6, 15558-15563.

[31] P. M. Csernica, J. R. McKone, C. R. Mulzer, W. R. Dichtel, H. D. Abruña, F. J. DiSalvo, ACS Catal. 2017, 7, 33753383.

[32] M. M. Jakšić, Int. J. Hydrogen Energy 2001, 26, 559-578.

[33] P. V. Guthrie, E. E. Stansbury, X-Ray and Metallographic Study of the Nickel-Rich Alloys of the Nickel-Molybdenum System. II, Report ORNL 3078, University Of Michigan Library, Oak Ridge, Tennessee, 1961.

[34] D. Harker, J. Chem. Phys. 1944, 12, 315-317.

[35] S. Saito, P. A. Beck, Trans. Met. Soc. AIME 1959, 215, 938-941.

[36] C. B. Shoemaker, D. P. Shoemaker, Acta Crystallogr. 1963, 16, 997-1009.

[37] L. Piccolo, L. Kibis, M.-C. De Weerd, E. Gaudry, J. Ledieu, V. Fournée, ChemCatChem 2017, 9, 2292-2296.

[38] M. C. Biesinger, B. P. Payne, L. W. M. Lau, A. Gerson, R. S. C. Smart, Surf. Interface Anal. 2009, 41, 324-332.

[39] D. R. Lide, Ed. , in CRC Handb. Chem. Phys., CRC Press, Boca Raton, Florida, 2013, Section 9, 78.

[40] P. A. Spevack, N. S. McIntyre, J. Phys. Chem. 2005, 96, 9029-9035.

[41] C. R. Clayton, Y. C. Lu, Surf. Interface Anal. 1989, 14, 6670.

[42] R. Zerdoumi, L. Rößner, M. Armbrüster, J. Electrochem. Soc. 2019, 166, F1079-F1087.

[43] L. F. Huang, M. J. Hutchison, R. J. Santucci, J. R. Scully, J. M. Rondinelli, J. Phys. Chem. C 2017, 121, 9782-9789.

[44] R. Parsons, J. Electroanal. Chem. Interfacial Electrochem. 1967, 13, 471.

[45] D. S. Hall, D. J. Lockwood, C. Bock, B. R. MacDougall, Proc. R. Soc. A Math. Phys. Eng. Sci. 2014, 471, 20140792.

[46] M. Alsabet, M. Grdeń, G. Jerkiewicz, Electrocatalysis 2014, 6, 60-71.

[47] D. S. Hall, C. Bock, B. R. MacDougall, J. Electrochem. Soc. 2013, 160, F235-F243.

[48] M.-S. Kim, J. Electrochem. Soc. 1998, 144, 1537-1543.

[49] A. F. Povey, A. A. Metcalfe, J. Electroanal. Chem. 1977, 84, 73-81.

[50] J. G. Highfield, E. Claude, K. Oguro, Electrochim. Acta 1999, 44, 2805-2814.

[51] D. S. Hall, C. Bock, B. R. MacDougall, ECS Trans. 2013, 50, 165-179.

[52] K. Hu, S. Jeong, M. Wakisaka, J. Fujita, Y. Ito, Metals (Basel). 2018, 8, 83. 


\section{Entry for the Table of Contents}

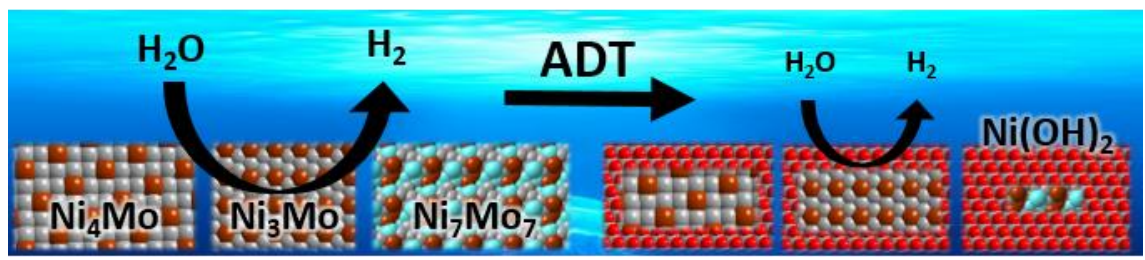

Bulk intermetallic compounds in the Mo-Ni system were investigated in the hydrogen evolution reaction in alkaline media by means of accelerated durability tests and thorough characterization. The often-claimed ordered Mo-Ni crystal structures, being responsible for high HER activities, proved to be unstable in the reaction media. Enhanced surface areas and thus higher apparent activities could be achieved by enforcing preferential molybdenum dissolution and/or selecting compounds with a high initial molybdenum content. 